\title{
AVALIAÇÃO PRELIMINAR DA REMOÇÃO DE ATIVIDADE ESTROGÊNICA DE UMA MISTURA DE DESREGULADORES ENDÓCRINOS EM ÁGUA UTILIZANDO CARVÃO ATIVADO GRANULAR
}

\author{
PRELIMINARY EVALUATION OF ESTROGENIC ACTIVITY REMOVAL OF ENDOCRINE \\ DISRUPTORS MIX IN WATER USING GRANULAR ACTIVATED CARBON
}

Juliana Palermo Evangelista dos Santos ${ }^{a}$, Lucas Martins Corrêa ${ }^{a}$, Pedro Antônio Alves Fernandesa, Sue Ellen Costa Bottrela ${ }^{a}$ Renata de Oliveira Pereira ${ }^{a}$

aniversidade Federal de Juiz de Fora

\begin{abstract}
juliana.palermo@engenharia.ufjf.br, lucas.mart.correa@gmail.com,pedro.antonio@engenharia.ufjf.br, sue.bottrel@uffif.edu.br, renata.pereira@ufif.edu.br
\end{abstract}

Submissão: 12 de setembro de 2021

Aceitação: 8 de novembro de 2021

\section{Resumo}

Os Desreguladores Endócrinos (DE) têm sido detectados em mananciais de abastecimento de água e sua remoção se faz necessária. Esses compostos são capazes de interagir ao sistema endócrino mesmo em concentrações muito baixas. Entre as tecnologias utilizadas em Estações de Tratamento de Água, o carvão ativado possui uma satisfatória relação custo-benefício e não forma subprodutos químicos no processo. Assim, avaliou-se a remoção da atividade estrogênica causada por uma mistura de estrona (E1), 17- $\beta$ estradiol (E2), 17- $\alpha$-etinilestradiol (EE2) e 4-n-nonilfenol (NP), em baixas concentrações, por Carvão Ativado Granular (CAG), em diferentes doses. O CAG foi caracterizado e foram utilizadas doses variando de 100 a $700 \mathrm{mg} \cdot \mathrm{L}^{-1}$. A quantificação da atividade estrogênica foi realizada pelo ensaio Yeast Estrogen Screen antes e após os experimentos. Observou-se que o CAG possuiu baixa quantidade de microporos e mesoporos, com a maior remoção da atividade estrogênica, de $91,6 \%$, ocorrendo na maior dose de CAG utilizada (700 mg.L1). Além disso, foi possível confirmar sinergia entre os $D E$, tornando a avaliação da atividade estrogênica uma importante ferramenta no estudo de DE. Portanto, conclui-se uma elevada remoção por CAG, todavia com atividade estrogênica remanescente podendo causar efeitos adversos à saúde.

Palavras-chave: ensaio YES; microcontaminantes; qualidade da água; tratamento de água.

\section{Abstract}

Endocrine Disruptors (ED) are being detected in water bodies. Their removal is necessary once they can interact with the endocrine system yet in extremely low concentrations. Among the technologies which are already in use in Water Treatment Plants, the activated carbon is cost-effective and does not produce chemical by-products during the treatment. Thus, was evaluated the estrogenic activity removal caused by a mixture of ED estrone (E1), 17- $\beta$-estradiol (E2), 17- $\alpha$-ethinylestradiol (EE2), and 4-n-nonylphenol (NP), in low concentrations, by Granular Activated Carbon (GAC), tested in different doses. The GAC was characterized, and the assay consisted of doses ranging from 100 to $700 \mathrm{mg} . \mathrm{L}^{-1}$. Before and after the experiments, the Yeast Estrogen Screen assay quantified estrogenic activity. Up to $91.6 \%$ removal of estrogenic activity was achieved, by the greater GAC dose, $700 \mathrm{mg} \cdot \mathrm{L}^{-1}$. Moreover, it was possible to confirm synergy between the ED, which makes the evaluation of estrogenic activity by DE an important tool. A high removal was achieved, however, the remnant estrogenic activity can cause side effects to human health.

Key words: microcontaminants; water quality; water treatment; YES assay.

\section{INTRODUÇÃO}

Os micropoluentes ou microcontaminantes são compostos que mesmo em baixas concentrações, na ordem de ng. $\mathrm{L}^{-1}$, são capazes de causar efeitos adversos à saúde humana e de outros animais de sangue quente. A presença de tais substâncias em corpos d'água decorre do lançamento in natura de efluentes domésticos ou 
industriais, do escoamento superficial de áreas agrícolas, da poluição difusa e, até mesmo, do lançamento de esgoto tratado em Estações de Tratamento de Esgoto (ETE) convencionais, devido à remoção incompleta nas mesmas. Sendo assim, pode-se concluir que esse grupo de compostos são continuamente introduzidos ao ambiente (ADEEL et al., 2017; AQUINO et al., 2013; BORNMAN et al., 2017; FISCHER, 2013; VILELA et al., 2018).

Os Desreguladores Endócrinos (DE) são uma das classes de micropoluentes, capazes de interagir com o sistema endócrino de maneira similar, antagônica ou bloqueadora à ação de hormônios naturalmente produzidos no organismo (USEPA, 2019). Como exemplos, citam-se pesticidas, fármacos, surfactantes e hormônios, comumente detectados em estações de tratamento de águas residuárias e em águas superficiais (CARVALHO et al., 2016; CUNHA et al., 2015). Nesse contexto, cabe ressaltar a relevância de alguns hormônios naturais como da estrona (E1) e do 17- $\beta$-estradiol (E2), auxiliares na manutenção da reprodução das células de diversos órgãos, tais como seios, pele e cérebro; do 17-a-etinilestradiol (EE2), hormônio sintético amplamente utilizado na fabricação de fármacos de tratamentos hormonais e do 4-n-nonilfenol (NP), um subproduto da degradação de surfactantes (BILA e DEZOTTI, 2007; ESTRADAARRIAGA e MIJAYLOVA, 2010; SOLÉ et al., 2000).

As Estações de Tratamento de Água (ETA) foram projetadas com o intuito de preservar a saúde humana, minimizando riscos associados à presença de patógenos, além da remoção de cor e turbidez (DI BERNARDO e DANTAS, 2005; LIBÂNIO, 2010). Nesses termos, o tratamento de água convencional, tipologia mais utilizada no país, se mostra eficaz. Contudo, esse tipo de tratamento possui limitações na remoção de alguns compostos químicos, dentre os quais despontam alguns desreguladores endócrinos (CHEN et al., 2007; LIMA et al., 2014; WESTERHOFF et al., 2005). Sendo assim, é clara a necessidade de estudos de técnicas adicionais para a remoção destes químicos, que somadas às tecnologias convencionais possam garantir à população a distribuição de uma água com riscos minimizados.

Em revisão bibliográfica feita por Azevedo (2019), alguns estudos envolvendo tecnologias de tratamento de água foram levantados para compilação de dados quanto à remoção de E1, E2,
EE2 e estriol (E3) avaliados individualmente. O estudo mostrou que, na etapa de clarificação, a maior remoção mediana reportada nos estudos avaliados foi de $20,5 \%$, confirmando ineficiência desse processo na remoção dos DE avaliados. No caso dos dados de remoção via cloração, fotólise e ozonização, que consistem em técnicas aplicadas na etapa de desinfecção, as remoções medianas máximas apresentadas no conjunto de pesquisas avaliadas foram de $96 \%, 98 \%$ e $100 \%$, respectivamente. Contudo, tais tecnologias são passíveis de formação de subprodutos, fato que deve ser verificado para a escolha do tratamento ou de suas condições ideais. É importante ressaltar que, tais subprodutos também podem causar atividade estrogênica e, ou toxicidade (PEREIRA et al., 2011).

Azevedo (2019) também avaliou estudos que utilizaram carvão ativado (CA) no tratamento de água, os quais relatam remoções de até $97 \%$, com ampla faixa de variação nas concentrações de $C A$, de 1 a $100 \mathrm{mg} \cdot \mathrm{L}^{-1}$. A utilização de carvão ativado é recomendada pela Agência de Proteção Ambiental dos Estados Unidos - USEPA (2019) para a remoção de microcontaminantes orgânicos e substâncias que conferem sabor, odor, cor, mutagenicidade e toxicidade à água. Vários autores consideram que o uso de CA possui uma relação custo-benefício satisfatória, simples aplicação, e, além disso, não forma subprodutos químicos durante o tratamento da água (BAÊTA et al., 2012; FORMICA et al., 2017; SENE, 2017).

As remoções de poluentes por carvão ativado ocorrem através do fenômeno de adsorção, no qual as substâncias que se encontram em solução, conhecidas como adsorvatos, se concentram na superfície de um sólido (adsorvente). O processo de adsorção decorre do contato entre o adsorvato, que pode apresentar-se em solução aquosa ou gasosa, com o adsorvente. Para tanto, podem ser utilizados reatores que operam em batelada, mantidos em agitação, ou colunas de leito fixo ou fluidizado (METCALF \& EDDY, 2016).

O carvão ativado é comercializado na forma granular (CAG), em pellets ou pulverizado (CAP). $O$ primeiro e segundo são normalmente utilizados em colunas de leito fixo e são passíveis de regeneração quando seus sítios de adsorção são saturados, tornando-o mais viável para uso contínuo em ETA, o que não ocorre com o CAP, por este motivo sendo normalmente utilizado para soluções pontuais (SENE, 2017). Ainda, é importante ressaltar que a dose de carvão a ser utilizada depende não só do volume de água a ser 
tratado, mas também da concentração das substâncias a serem removidas. Além disso, ressalta-se a importância de ensaios de tratabilidade com o efluente alvo, uma vez que os carvões possuem especificidades que variam de acordo com seus precursores ou técnicas de produção, podendo apresentar eficiências distintas para diferentes compostos (METCALF \& EDDY, 2016).

No que se diz respeito ao monitoramento da concentração de DE em matrizes aquosas, determinações podem ser feitas por análises químicas instrumentais, que trazem como resultado a concentração de compostos específicos previamente determinados, ou análises in vivo ou in vitro, que reportam a atividade estrogênica relativa de uma amostra. Destaca-se o ensaio Yeast Estrogen Screen (YES), técnica in vitro que apresenta alta especificidade para a detecção de substâncias estrogênicas e elevada sensibilidade para a quantificação da atividade estrogênica relativa dos DE que compõem a amostra. $O$ ensaio possui como vantagem a valoração da atividade estrogênica como um todo, uma vez que algumas misturas de DE podem resultar em efeitos sinérgicos ou, até mesmo antagônicos (BILA, 2005; ROUTLEDGER \& SUMPTER, 1996).

$\mathrm{Em}$ busca na literatura, não foram encontrados trabalhos que valeram do ensaio YES para avaliar a remoção da atividade estrogênica de amostras aquosas através da adsorção em carvão ativado, seja ele granular ou pulverizado. Ademais, os estudos existentes com esse escopo trabalharam com concentrações iniciais relativamente elevadas dos $D E$, chegando a 20 mg. $\mathrm{L}^{-1}$, como pôde ser observado no estudo de Ogata et al. (2011). Tais valores são atípicos por não serem comumente encontrados em corpos hídricos, como mostrou a revisão bibliográfica de Resende et al. (2017) a qual, após tratamento dos dados da literatura, reportou medianas de até 37,4 ng. $\mathrm{L}^{-1}$, demonstrando a necessidade de mais estudos que avaliem a eficiência do uso do carvão ativado em amostras com concentrações de DE próximas àquelas que realmente ocorrem nas águas superficiais.

Assim, o presente trabalho investigou o potencial do uso de CAG na remoção da atividade estrogênica causada por uma combinação de DE em água (E1, E2, EE2 e NP), em baixas concentrações, utilizando o ensaio YES como ferramenta para a avaliação das remoções.

\section{METODOLOGIA}

\subsection{Materiais de estudo}

A água utilizada nos experimentos foi coletada em região preservada de Torreões (Minais Gerais, Brasil) e possuía qualidade físicoquímica semelhante à pós-filtração de ETA. Essa água foi dopada com uma combinação dos desreguladores endócrinos E1 ( $\geq 99 \%)$, E2 ( $\geq 98 \%)$, EE2 ( $\geq 98 \%$ ) e NP (P.A.), todos obtidos da SigmaAldrich $^{\circledR}$, com as respectivas concentrações de: 100 ng. $L^{-1}, 100$ ng. $L^{-1}, 50$ ng. $L^{-1}$ e 1000 ng. $L^{-1}$. Tais valores foram estabelecidos com base em valores reportados na literatura nacional e internacional, para que representassem a realidade de concentrações encontradas em águas superficiais (DING et al., 2001; JOHNSON et al., 2000; KOLPIN et al., 2002; MOREIRA et al., 2009; MOREIRA et al., 2011; RESENDE et al., 2017).

O carvão ativado utilizado no experimento foi do tipo granular (CAS 7440-44-0), da marca Isofar ${ }^{\circledR}$, com densidade aparente variando de 0,25 a $0,65 \mathrm{~g} \cdot \mathrm{cm}^{-3}$.

De acordo com a Organização Mundial de Saúde - WHO (2011), algumas propriedades químicas do adsorvato influenciam na adsorção, tais quais: a solubilidade em água, o coeficiente de partição octanol-água (log Kow) e a constante de acidez (pKa) (BOTTREL, 2012).

Assim, para posterior discussão dos resultados, apresentam-se as propriedades dos DE utilizados no estudo na Tabela 1.

\subsection{Métodos analíticos e equipamentos}

Para caracterização da água submetida aos ensaios, foram realizadas as seguintes análises: potencial hidrogeniônico $(\mathrm{pH})$, condutividade elétrica (CE), cor aparente, turbidez, temperatura e determinação da atividade estrogênica. Ainda, durante os ensaios, foram feitas medições da temperatura e do $\mathrm{pH}$ das amostras

Os métodos e respectivos equipamentos utilizados encontram-se sumarizados no Quadro 1. Todos os ensaios apresentados neste trabalho foram realizados no Laboratório de Qualidade Ambiental (LAQUA), da Faculdade de Engenharia da Universidade Federal de Juiz de Fora (UFJF).

\subsection{Caracterização do carvão ativado}

Para a caracterização do carvão ativado foram feitas análises do $\mathrm{pH}$ do ponto de carga zero $\left(\mathrm{pH}_{\mathrm{pcz}}\right)$, de acordo com Bottrel (2012) apud RIVERA-UTRILLA (2000); Índice de Azul de Metileno (IAM), segundo Piza (2008), que teve seu 
estudo baseado na norma JIS-K-1474/2014 do Japonese Industrial Standard; e Número de lodo, de acordo com a ABNT NBR MB-3410 (1991).

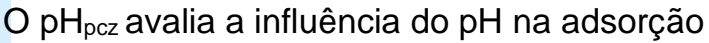
de solutos (adsorvatos) na superfície de sólidos (adsorventes) e é definido como o pH no qual o balanço de cargas é nulo. Para o ensaio de $\mathrm{pH}_{\mathrm{pcz}}$, primeiramente, foram adicionados à 11 Erlenmeyers, $50 \mathrm{~mL}$ de solução aquosa de $\mathrm{NaCl}$ $0,1 \mathrm{~mol} . \mathrm{L}^{-1}$, nos quais foram feitos ajustes de $\mathrm{pH}$ de 2 a 12, variando em uma unidade, por meio da adição de soluções aquosas de $\mathrm{HCl} 0,1 \mathrm{~mol}^{-L^{-1} \mathrm{e}}$ $\mathrm{NaOH} 0,1$ mol.L-1. Em seguida, adicionou-se 0,15 $\mathrm{g}$ do CAG em cada recipiente. Os Erlenmeyers permaneceram em agitação a 120 rpm em shaker Solab ${ }^{\circledR}$, modelo SL $180 / D$, durante 48 horas para garantir estabilização do $\mathrm{pH}$. Após este tempo foram refeitas as medições de $\mathrm{pH}$ e posteriormente foi confeccionado um gráfico de $\mathrm{pH}_{\text {final }} \times \mathrm{pH}_{\text {inicial, }}$, sendo a intersecção entre as duas linhas o resultado do $\mathrm{pH}$ do ponto de carga zero.

Tabela 1: Propriedades físico-químicas dos desreguladores endócrinos utilizados no estudo

\begin{tabular}{|c|c|c|c|c|c|c|}
\hline Composto & $\begin{array}{l}\text { Fórmula } \\
\text { Molecular }\end{array}$ & $\begin{array}{l}\text { Massa Molar } \\
\left(\mathrm{g} \cdot \mathrm{mol}^{-1}\right)\end{array}$ & $\begin{array}{l}\text { Comprimento } \\
\text { molecular }(\mathrm{nm})\end{array}$ & $\begin{array}{c}\text { Solubilidade } \\
\text { em água } \\
\left(\mathrm{mg} \cdot \mathrm{L}^{-1}\right)\end{array}$ & $\begin{array}{l}\text { Log } \\
K_{\text {ow }}\end{array}$ & $\mathrm{pK}_{\mathrm{a}}$ \\
\hline Estrona (E1) & $\mathrm{C}_{18} \mathrm{H}_{22} \mathrm{O}_{2}$ & 270,4 & 1,39 & 13 & 3,13 & 10,5 \\
\hline $17-\beta$-estradiol (E2) & $\mathrm{C}_{18} \mathrm{H}_{24} \mathrm{O}_{2}$ & 272,4 & 1,39 & 3,6 & 4,01 & 10,4 \\
\hline $\begin{array}{l}\text { 17- } \alpha \text {-etinilestradiol } \\
\text { (EE2) }\end{array}$ & $\mathrm{C}_{20} \mathrm{H}_{24} \mathrm{O}_{2}$ & 296,4 & 1,48 & 11 & 3,67 & 10,4 \\
\hline 4-n-nonilfenol (NP) & $\mathrm{C}_{15} \mathrm{H}_{24} \mathrm{O}$ & 220,4 & 1,79 & 7 & 5,76 & 10,0 \\
\hline
\end{tabular}

Quadro 1: Métodos e equipamentos utilizados nas análises

\begin{tabular}{|c|c|c|c|}
\hline Análise & Método & Equipamento & Referência \\
\hline $\mathrm{pH}$ & $4500-\mathrm{H}^{+} \mathrm{B}$ & HANNA $^{\circledR}$, HI 8424 & $\begin{array}{l}\text { APHA, AWWA e } \\
\text { WEF (2005) }\end{array}$ \\
\hline CE & 2510 & Gehaka $^{\circledR}$, CG 1800 & $\begin{array}{l}\text { APHA, AWWA e } \\
\text { WEF (2005) }\end{array}$ \\
\hline Cor Aparente & 2120 & Espectrofotômetro Hach ${ }^{\circledR}$, DR6000 & $\begin{array}{l}\text { APHA, AWWA e } \\
\text { WEF (2005) }\end{array}$ \\
\hline Turbidez & $2130 B$ & Del Lab ${ }^{\circledR}$, DLT WV & $\begin{array}{l}\text { APHA, AWWA e } \\
\text { WEF (2005) }\end{array}$ \\
\hline $\begin{array}{l}\text { Atividade } \\
\text { Estrogênica }\end{array}$ & $\begin{array}{l}\text { Ensaio } \\
\text { YES }\end{array}$ & $\begin{array}{c}\text { Leitora de placas Thermo Scientific }{ }^{\circledR}, \\
\text { Multiskan FC }\end{array}$ & $\begin{array}{c}\text { Routledger e } \\
\text { Sumpter (1996) }\end{array}$ \\
\hline
\end{tabular}

Fonte: Autoria própria

O Índice de Azul de Metileno é um parâmetro comumente utilizado para a caracterização do carvão ativado quanto à microporosidade e mesoporosidade. Para realização do ensaio, $1 \mathrm{~g}$ de Azul de Metileno (AM) foi seco a fim de eliminar a umidade do corante. Logo após foram preparadas duas soluções do Azul de Metileno em tampão fosfato, a primeira na concentração de 24 mg. L-1 $^{-1}$ e a segunda, na concentração de 1200 mg. $\mathrm{L}^{-1}$. Para a pesagem do corante foi utilizada balança analítica (Shimadzu ${ }^{\circledR}$, ATY224).
Com a primeira solução foi preparada uma curva de calibração, com as seguintes concentrações de AM: $0,24 \mathrm{mg} \cdot \mathrm{L}^{-1} ; 0,48 \mathrm{mg} \cdot \mathrm{L}^{-1}$; $0,96 \mathrm{mg} \cdot \mathrm{L}^{-1} ; 1,2 \mathrm{mg} \cdot \mathrm{L}^{-1} ; 2,40 \mathrm{mg} \cdot \mathrm{L}^{-1} ; 4,8 \mathrm{mg} \cdot \mathrm{L}^{-1} ; 9,6$ mg. $\mathrm{L}^{-1} ; 14,4 \mathrm{mg} \cdot \mathrm{L}^{-1} ; 19,2 \mathrm{mg} \cdot \mathrm{L}^{-1}$. A absorbância das amostras foi lida no comprimento de onda de 665 nm, em espectrômetro Hach ${ }^{\circledR}$ DR 6000.

Em seguida, após testes preliminares, foram adicionados a frascos com tampas $3 \mathrm{~g} ; 5 \mathrm{~g} ; 10 \mathrm{~g}$; $15 \mathrm{~g} ; 20 \mathrm{~g}$ de $\mathrm{CA}$, nos quais foram adicionados 25 $\mathrm{mL}$ da solução $A M 1200 \mathrm{mg} \cdot \mathrm{L}^{-1}$. Os frascos foram 
mantidos em agitação por 30 minutos a 160 rpm, filtrados em filtro qualitativo, e, então alíquotas foram encaminhadas à leitura espectrofotométrica para quantificação da concentração final de AM (Equação 1).

$$
\mathrm{Q}=\frac{(1200-\mathrm{C}) \times 0,025}{\mathrm{~S}_{\mathrm{c}}}
$$

Onde:

Q $\left(\mathrm{mg}^{\mathrm{g}} \mathrm{g}^{-1}\right)$ : quantidade de azul de metileno adsorvido;

C (mg. $\left.\mathrm{L}^{-1}\right)$ : concentração final de azul de metileno

- calculado pela curva -

$\mathrm{S}_{\mathrm{c}}(\mathrm{g})$ : massa de carvão;

1200 (mg. $\left.\mathrm{L}^{-1}\right)$ : concentração inicial do azul de metileno;

0,025 (L): volume da solução-trabalho.

Por fim, expresso na Equação 2, com auxílio de isotermas, foi determinado o Índice de Azul de Metileno, segundo o método supracitado, padronizado a ser determinado na concentração final de AM igual a $0,24 \mathrm{mg} \cdot \mathrm{L}^{-1}$.

$$
\mathrm{IAM}=\frac{\mathrm{Q}^{\prime}}{1,2}
$$

Onde:

IAM (mL. $\left.\mathrm{g}^{-1}\right)$ : Índice de Azul de Metileno;

Q' (mg. $\left.\mathrm{g}^{-1}\right)$ : quantidade de AM adsorvido para concentração final de $0,24 \mathrm{mg} \cdot \mathrm{L}^{-1}$;

1,2 (g.L-1): concentração inicial do azul de metileno.

O último parâmetro de caracterização do CAG de estudo foi o Número de lodo, que assim como o Índice de Azul de Metileno é analisado com o intuito de estimar a porosidade do carvão. Seguindo à norma, o processo foi iniciado moendo-se o carvão, o qual foi direcionado à secagem em estufa SL-101 Solab ${ }^{\circledR}$ por 3 horas a $130{ }^{\circ} \mathrm{C}$, para posteriormente ser resfriado em dessecador até que atingisse temperatura ambiente. Em seguida, 1,000 g do CA seco foi pesado e transferido para um Erlenmeyer de 250 $\mathrm{mL}$, com boca esmerilhada.

Logo após, foram adicionados $10 \mathrm{~mL}$ de solução de ácido clorídrico, deixados em ebulição por 30 segundos em chapa quente, posteriormente resfriados à temperatura ambiente, onde foram adicionados $100 \mathrm{~mL}$ de solução de iodo $0,1 \mathrm{~N}$. O Erlenmeyer foi imediatamente fechado e agitado vigorosamente por 30 segundos.
A solução resultante foi filtrada por gravidade, em funil de vidro, com papel de filtro qualitativo, sendo que os primeiros $20 \mathrm{~mL}$ do filtrado foram rejeitados. O volume filtrado foi homogeneizado com auxílio de um bastão de vidro antes da transferência de $50 \mathrm{~mL}$ do mesmo para um Erlenmeyer de $250 \mathrm{~mL}$. Assim, foi feita uma titulação com solução de tiossulfato de sódio de $0,1 \mathrm{~N}$ até que o volume atingisse uma coloração amarelada, para que em seguida fossem adicionados $2 \mathrm{~mL}$ de solução indicadora de amido $0,5 \%$ e a titulação prosseguisse até que a solução deixasse de apresentar coloração azul. Por fim, o índice foi obtido de acordo com a tabela do Anexo A da norma MB-3410 (1991).

\subsection{Ensaios de adsorção}

Os ensaios foram feitos em batelada, com agitação e temperatura controladas, uma vez que ambos os parâmetros são considerados variáveis importantes neste tipo de procedimento com o carvão ativado. Outras duas variáveis determinantes são a concentração do adsorvato, neste caso a combinação de $100 \mathrm{ng} \cdot \mathrm{L}^{-1}$ de $\mathrm{E} 1,100$ ng. $L^{-1}$ de E2, 50 ng. $L^{-1}$ de EE2 e 1000 ng. $L^{-1}$ de NP, e a massa do adsorvente, objeto da presente etapa (NASCIMENTO et al., 2014).

Para dar início à determinação da capacidade adsortiva do Carvão Ativado Granular de estudo, foram adotadas as concentrações de $1 \mathrm{mg} \cdot \mathrm{L}^{-1} \mathrm{e}$ $100 \mathrm{mg} \cdot \mathrm{L}^{-1}$ do mesmo, que representavam, respectivamente, a menor e a maior massa utilizadas por outros autores em contexto similar ao do presente trabalho. $O$ intuito desses experimentos foi a obtenção de resultados preliminares para a escolha de uma faixa de concentrações, tornando possível a obtenção de isotermas de adsorção.

O processo se iniciou com a adição da mistura dos $D E$ em um volume de $3 L$ da água de estudo, posteriormente dividida em três porções de $1 \mathrm{~L}$ devidamente acondicionadas. Assim, em dois dos béqueres utilizados, foram adicionadas as massas supracitadas de carvão e deixadas em agitação por 2 horas, pois de acordo com a Sociedade Americana de Ensaios e Materiais - ASTMInternacional (2008), este tempo de contato normalmente é o suficiente para ocorrer equilíbrio entre 0 adsorvente e o adsorvato. Após este período as amostras foram filtradas em filtro qualitativo, de modo a separar o adsorvente da solução, interrompendo a reação. Ressalta-se que o terceiro béquer foi mantido sem carvão para a 
quantificação da concentração inicial de atividade estrogênica da mistura.

Após a obtenção dos resultados preliminares da adsorção, foi feito um novo ensaio com seis diferentes concentrações de carvão, variando em

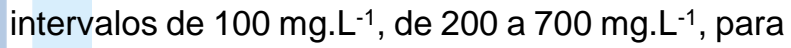
obtenção dos dados necessários para estudo das isotermas de adsorção. Ressalta-se ainda, que foram utilizados tempo de contato de 2 horas e volumes de $1 \mathrm{~L}$ para as amostras dopadas.

Em continuidade aos ensaios de adsorção sobreditos, todas as amostras obtidas foram direcionadas ao processo de extração em fase sólida.

\subsection{Extração em Fase Sólida (SPE)}

A Extração em Fase Sólida (SPE) tem como principal objetivo concentrar as substâncias estrogênicas presentes na amostra. Este procedimento foi feito de acordo com Pereira (2011), com adaptações, utilizando cartuchos C18 ODS SampliQ (500 mg, $6 \mathrm{~mL}$ ) e Manifold de 20 posições funcionando sob pressão de vácuo de uma bomba.

O início do método se dá pelo condicionamento, realizado através da passagem de $6 \mathrm{~mL}$ de hexano, $2 \mathrm{~mL}$ de acetona, $6 \mathrm{~mL}$ de metanol e $10 \mathrm{~mL}$ de água deionizada ajustada com $\mathrm{pH} 3$, nessa ordem, sendo todos os reagentes com de grau de pureza P.A. Em continuidade, foi feita a eluição das amostras com $300 \mathrm{~mL}$. O volume a ser utilizado nesta etapa depende do fator de concentração desejado para cada amostra.

Posteriormente, o cartucho foi mantido a vácuo para secagem por aproximadamente 10 minutos. Os analitos foram eluidos em seguida utilizando $4 \mathrm{~mL}$ de acetona. Por fim, o volume final do extrato obtido foi completamente seco em fluxo de gás nitrogênio e, para a execução do ensaio YES, foi adicionado ao frasco etanol absoluto para transferência dos analitos para fase orgânica.

Com o intuito de verificar que a água de estudo não apresentava atividade estrogênica previamente, e para controle dos ensaios, esta também foi testada.

\subsection{Ensaio YES}

$O$ ensaio YES, técnica in vitro de quantificação de atividade estrogênica, foi realizado segundo metodologia de Routledger e Sumpter (1996), com adaptações realizadas por Bila (2005). O composto clorofenol vermelho- $\beta$-D- galactopiranosida (CPRG) foi adquirido da marca Merck $^{\circledR}$. Todos os reagentes utilizados no ensaio foram obtidos da Sigma-Aldrich ${ }^{\circledast}$ ou da Synth ${ }^{\circledR}$, com elevado grau de pureza.

Das amostras obtidas na etapa de SPE, aquelas que foram tratadas com o carvão ativado, bem como a água não dopada, foram ressuspendidas com $1 \mathrm{~mL}$ de etanol absoluto, de modo que ficassem 300 vezes mais concentradas em relação ao início do ensaio. Para a amostra inicial, ou seja, com a combinação de DE (antes do tratamento), a ressuspensão ocorreu com $3 \mathrm{~mL}$, de modo que esta ficasse apenas 100 vezes mais concentrada, uma vez que devido à elevada concentração de atividade estrogênica presente inicialmente na água dopada, os resultados superariam o valor máximo da curva padrão do ensaio YES, o que tornaria inviável a quantificação inicial.

As análises foram realizadas em placas de 96 poços, em duplicata, intercaladas com fileiras de branco, contendo apenas etanol e meio de análise, sendo este último composto por $25 \mathrm{~mL}$ de meio de cultivo, $25 \mu \mathrm{L}$ da levedura Saccharomyces cerevisiae e $200 \mu \mathrm{L}$ de CPRG em solução com água deionizada, com concentração de $10 \mathrm{mg} \cdot \mathrm{L}^{-1}$.

Inicialmente foram preparadas placas de diluição. Para tal, foram dispostos nas fileiras 100 $\mu \mathrm{L}$ de etanol, com exceção do primeiro poço, o qual recebeu o volume de $200 \mu \mathrm{L}$ de amostra ou de padrão de E2, ou de branco (apenas etanol). Posteriormente, foram realizadas diluições seriais de 1:1 a partir do primeiro poço.

A solução padrão de E2 em etanol absoluto possuía concentração igual a $54,48 \mu \mathrm{g} \cdot \mathrm{L}^{-1}$, resultando, após as diluições seriais em curva padrão de concentrações variando de $27,24 \mu \mathrm{g} . \mathrm{L}^{-1}$ a 1,3 ng. $\mathrm{L}^{-1}$, utilizada para os cálculos finais da quantificação de atividade estrogênica.

Após a diluição, $10 \mu \mathrm{L}$ de cada poço destas placas foram transferidos para as placas de análise, com auxílio de uma pipeta automática multicanal. Em seguida, este volume foi deixado evaporar totalmente e então foram adicionados $200 \mu \mathrm{L}$ do meio de análise em cada poço.

Ao término desta etapa, as placas foram seladas e colocadas em agitação a $100 \mathrm{rpm}$ no shaker de agitação orbital, durante 1 minuto. Posteriormente, as placas foram encaminhadas à estufa, com temperatura ajustada a $32^{\circ} \mathrm{C}$, na qual foram acondicionadas por 72 horas. Após o tempo de incubação, estas foram submetidas à uma leitura espectrofotométrica, através da leitora de placas, nos comprimentos de onda de 539 e 620 
$\mathrm{nm}$, que correspondem ao comprimento máximo de absorção da cor formada (rosa) e avaliação da turbidez, respectivamente. Por fim, os dados obtidos foram ajustados de acordo com uma curva sigmoidal do tipo dose-resposta, utilizando o software Origin $8.0^{\circledR}$. Assim, foram calculados os valores da atividade estrogênica das amostras, reportados em equivalente de estradiol (EQ-E2).

Obtidos esses resultados, de acordo com valores reportados por Beck et al. (2006), foi calculada uma potência estrogênica relativa teórica para a mistura dos desreguladores endócrinos, causada pela diferença das características físico-químicas desses compostos (Tabela 1). As potências estrogênicas relativas teóricas de cada composto representam a atividade estrogênica causada por estes em relação àquela causada pelo 17- $\beta$-estradiol, demonstradas na Tabela 2.

Tabela 2: Potência estrogênica relativa teórica individual dos desreguladores endócrinos

\begin{tabular}{c|c|c}
\hline$D E$ & $\begin{array}{c}\text { Potência estrogênica relativa teórica } \\
(\mathrm{P})(\mathrm{EQ}-\mathrm{E} 2)\end{array}$ & $\begin{array}{c}\text { Concentração } \\
\text { na solução } \\
(\mathrm{C})\left(\mathrm{ng} \cdot \mathrm{L}^{-1}\right)\end{array}$ \\
\hline E1 & $2,5.10^{-1}$ & 100 \\
E2 & 1 & 100 \\
EE2 & 1,25 & 50 \\
NP & $1,8.10^{-5}$ & 1000 \\
\hline
\end{tabular}

Fonte: Beck et al. (2006)

Em posse dos valores sobreditos, foi feito um cálculo da potência estrogênica relativa teórica total dos DE, através do somatório do produto das potências teóricas individuais com as concentrações de cada composto na solução (Equação 3).

$$
\sum C \times P
$$

Assim, para se avaliar a exatidão da metodologia utilizada, o valor teórico calculado com a Equação 3 para as concentrações da solução inicial da mistura dos DE foi comparado com o resultado obtido através do ensaio YES para a mesma solução.

\subsection{Elaboração das isotermas}

As isotermas foram elaboradas, com auxílio

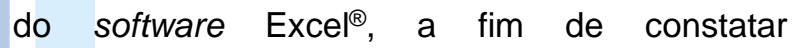
graficamente os resultados obtidos nos ensaios de adsorção em função da quantidade de material adsorvido por massa de adsorvente (DI BERNARDO e DANTAS, 2005; METCALF e EDDY, 2016). Para sua obtenção, os dados foram ajustados aos dois modelos matemáticos experimentais mais difundidos, desenvolvidos por Freundlich (Equação 4) e Langmuir (Equação 5).

$$
\frac{x}{m}=K_{f} \times C_{e}^{\frac{1}{n}}
$$

Onde:

$\mathrm{x} / \mathrm{m}\left(\mathrm{ng} \cdot \mathrm{g}^{-1}\right)$ : massa de adsorvato por unidade de massa de adsorvente;

$\mathrm{K}_{\mathrm{f}}\left(\mathrm{ng} \cdot \mathrm{g}^{-1} \cdot\left(\mathrm{L}^{\mathrm{n} n \mathrm{~g}^{-1}}\right)^{1 / \mathrm{n}}\right)$ : constante de adsorção de Freundlich;

$\mathrm{C}_{e}$ (ng. $\mathrm{L}^{-1}$ ): concentração de equilíbrio do adsorvato na solução após a adsorção;

1/n: coeficiente empírico.

$$
\frac{x}{m}=\frac{a \times b \times C_{e}}{1+b \times C_{e}}
$$

Onde:

$\mathrm{C}_{e}$ (ng. $\mathrm{L}^{-1}$ ): concentração de equilíbrio do adsorvato na solução após a adsorção;

$\mathrm{x} / \mathrm{m}\left(\mathrm{ng} \cdot \mathrm{g}^{-1}\right)$ : massa de adsorvato por unidade de massa de adsorvente;

a, b: constantes empíricas.

Após ajuste dos dados ao modelo e obtenção dos gráficos, foram analisados os valores do coeficiente de correlação $\left(R^{2}\right)$ da linha de tendência para avaliação da representatividade do modelo e determinação da constante de adsorção (METCALF e EDDY, 2016). O estudo das isotermas torna-se necessário uma vez que as constantes empíricas supracitadas em ambos os modelos particularizam os ensaios, não podendo ser obtidos sob correlações gerais (FOUST et al., 1982). 


\section{RESULTADOS, ANÁLISE E DISCUSSÃO}

\subsection{Caracterização do carvão ativado}

O resultado obtido para o $\mathrm{pH}_{\mathrm{pcz}}$ do $\mathrm{CA}$ foi igual a 7, ponto de intersecção das curvas de $\mathrm{pH}$ inicial com o pH final, caracterizando esse como o pH em que sua superfície se apresenta neutra (Figura 1).

O Índice de Azul de Metileno é um parâmetro comumente utilizado para a caracterização do carvão ativado quanto à porosidade devido ao fato de a molécula do Azul de Metileno (AM) ser adsorvida nos microporos e nos mesoporos dos adsorventes, no intervalo de 0,8 a $50 \mathrm{~nm}$. Assim, quanto maiores os valores encontrados para este índice, maior a capacidade do CA de estudo adsorver moléculas de tamanhos similares ao próprio azul de metileno e dentro do intervalo supracitado (SENE, 2017).
Desta forma, após obtenção da curva de calibração do $\mathrm{AM}$, foi possível determinar a concentração final de AM nos ensaios e, consequentemente, a massa do corante adsorvida (Tabela 3).

Em continuidade ao procedimento, de acordo com a metodologia utilizada, o IAM foi calculado de acordo com a Equação 2. Desta forma, os dados obtidos foram tratados de acordo com os modelos de isotermas de Freundlich e Langmuir, mostradas nas Figuras 2 e 3, respectivamente. Ressalta-se que de acordo com Metcalf e Eddy (2016), os modelos de isotermas foram aplicados utilizando as formas lineares das equações 4 e 5 , de modo que as isotermas pudessem ser comparadas em relação ao ajuste linear e desta forma fosse escolhida a que apresentasse melhor $\mathrm{R}^{2}$.

Figura 1: Gráfico do pH de Ponto de Carga Zero do CAG

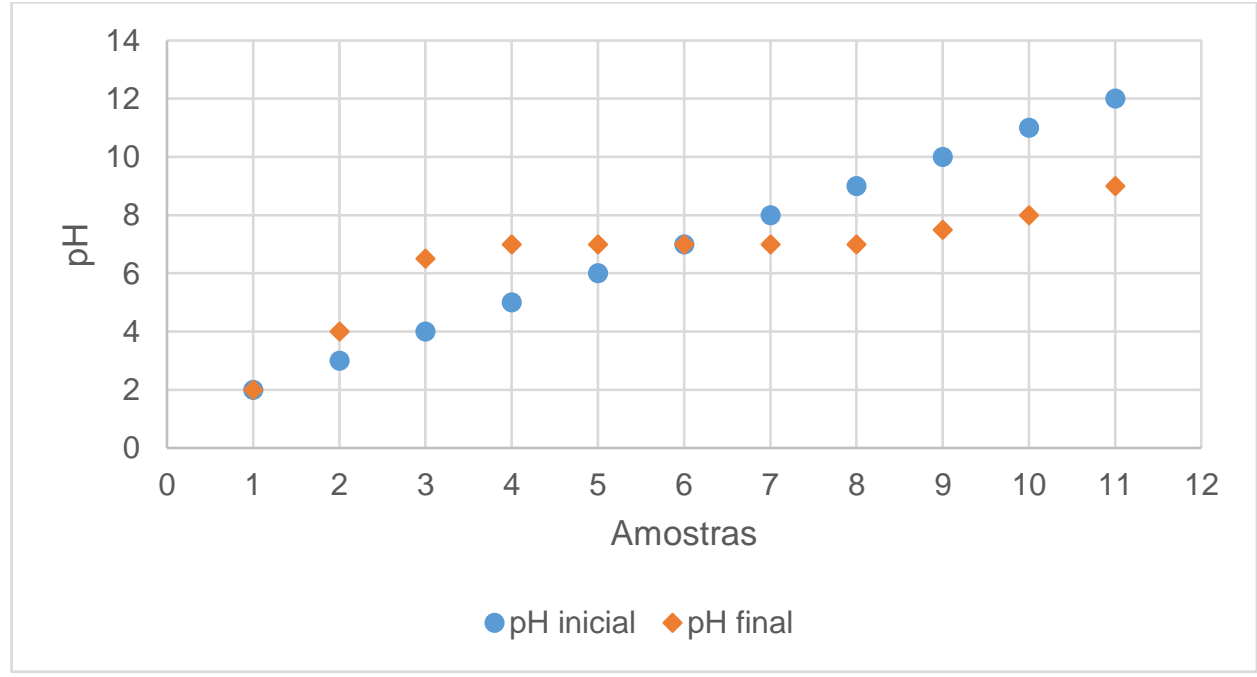

Fonte: Autoria própria

Tabela 3: Valores de concentração de equilíbrio, e massa de AM adsorvida nos ensaios com diferentes concentrações de carvão.

\begin{tabular}{c|c|c}
\hline Massa inicial de CAG $(\mathrm{g})$ & $\begin{array}{c}\text { Concentração final AM (C) } \\
\left(\mathrm{mg} \cdot \mathrm{L}^{-1}\right)\end{array}$ & AM adsorvido (Q) $\left(\mathrm{mg} \cdot \mathrm{g}^{-1}\right)$ \\
\hline 3 & 49,43 & 9,59 \\
5 & 12,39 & 5,94 \\
10 & 1,55 & 3,00 \\
15 & 0,29 & 2,00 \\
20 & 0,02 & 1,50 \\
\hline
\end{tabular}

Fonte: Autoria própria 
Figura 2: Isoterma de Freundlich obtida no tratamento dos dados dos ensaios de adsorção com AM em meio aquoso em escala dilog

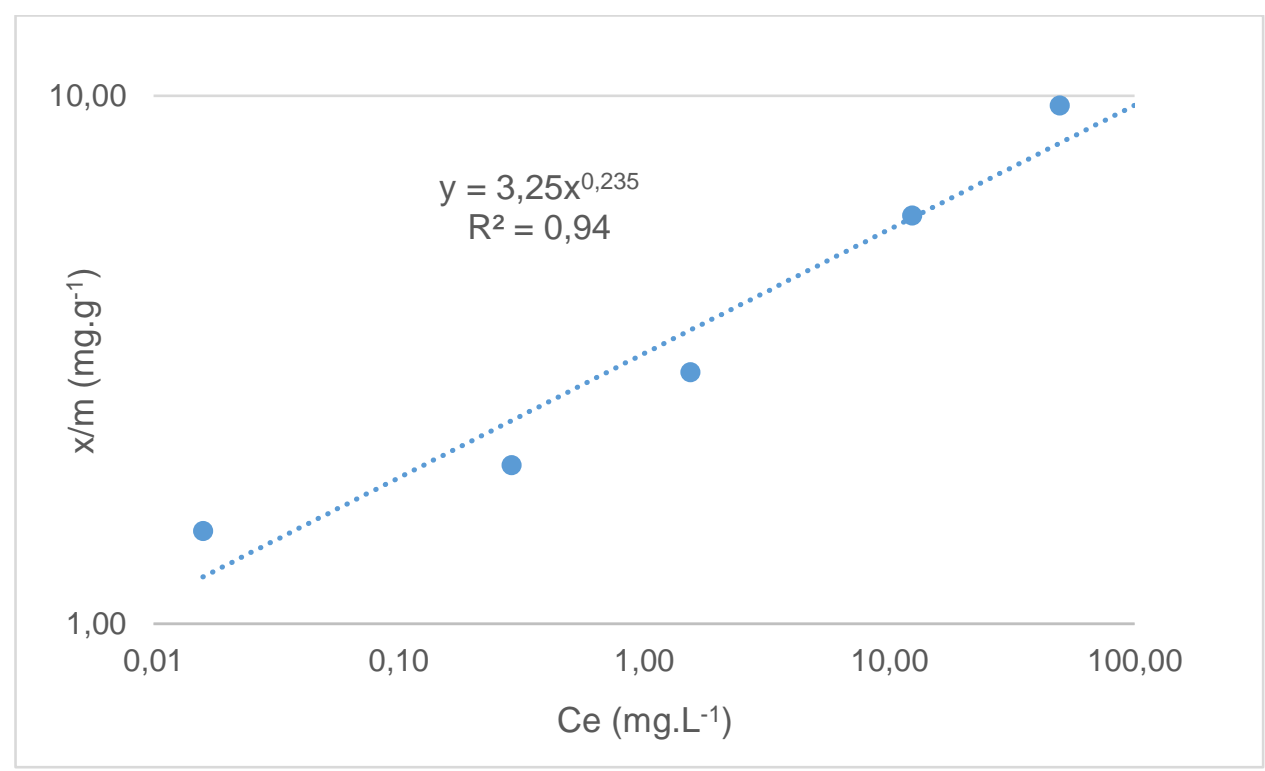

${ }^{*} \mathrm{x} / \mathrm{m}$ : massa de adsorvato por unidade de massa de adsorvente;

${ }^{* \star} \mathrm{Ce}$ : concentração de equilíbrio do adsorvato na solução após a adsorção.

Fonte: Autoria própria

Figura 3: Isoterma de Langmuir obtida no tratamento dos dados dos ensaios de adsorção com AM em meio aquoso.

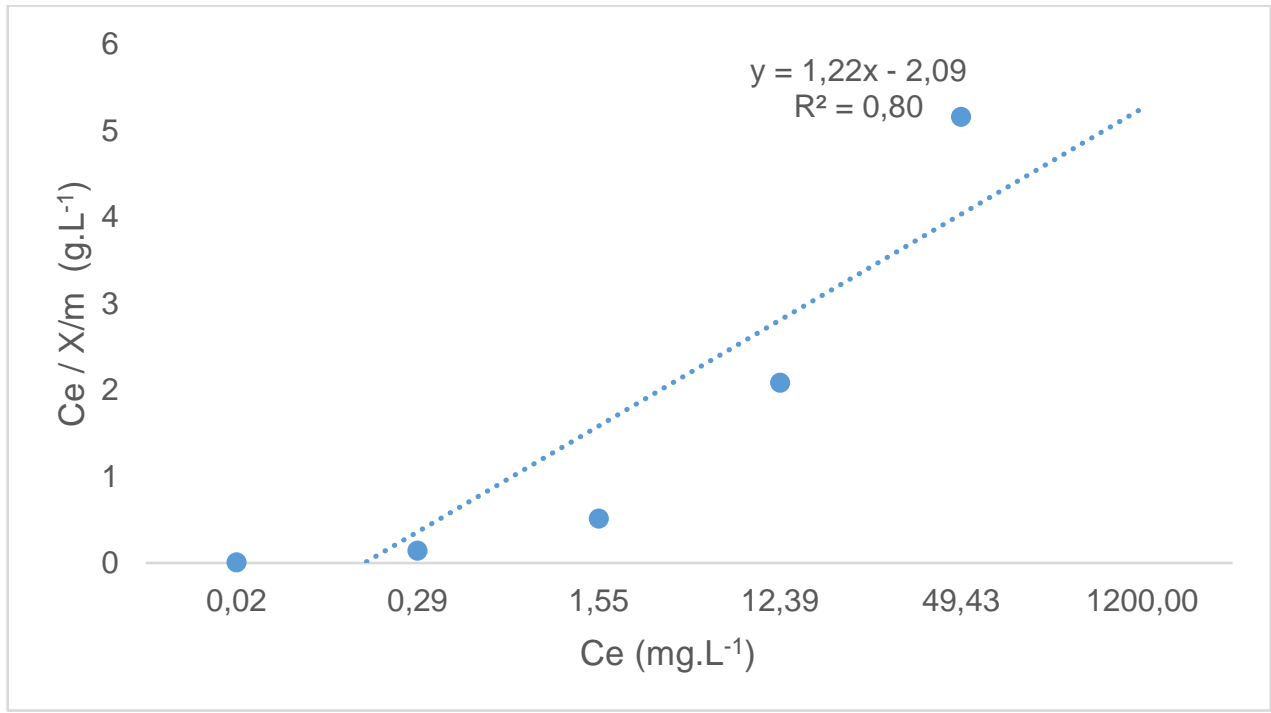

${ }^{*}$ Ce: concentração de equilíbrio do adsorvato na solução após a adsorção;

${ }^{* *} \mathrm{x} / \mathrm{m}$ : massa de adsorvato por unidade de massa de adsorvente.

Fonte: Autoria própria

Pode-se perceber que o modelo de Freundlich se mostrou mais adequado, através do qual foi obtida a equação de ajuste dos dados utilizando-se de linha de tendência de potência, em escala dilog tal como explicado por Metcalf $e$ Eddy (2016). Assim, através da Equação 4, foi obtida uma quantidade de azul de metileno adsorvido $(\mathrm{x} / \mathrm{m})$ igual a $2,32 \mathrm{mg} \cdot \mathrm{g}^{-1}$ e Índice de
Azul de Metileno de 1,93 mg. $\mathrm{g}^{-1}$ neste estudo.

Nas normas brasileiras não existem valores recomendados para o IAM, contudo o valor encontrado está muito aquém dos valores reportados por outros autores que utilizaram o mesmo tipo de adsorvente. Por exemplo, no estudo realizado por Di Bernardo e Dantas (2005), o valor mínimo reportado para o IAM foi de 11,42 
$\mathrm{mg} \cdot \mathrm{g}^{-1}$. Para fins de comparação do considerado eficiente na remoção de moléculas de características semelhantes à de Azul de metileno, os autores ainda citam que o valor mínimo exigido no Marrocos é de $180 \mathrm{mg}^{-\mathrm{g}^{-1}}$.

Os valores do índice diminuem com o aumento da massa de carvão adicionada para obtenção da adsorção desejada. Durante os experimentos, foi necessária a adição de mais de $15 \mathrm{~g}$ do CAG para a realização do ensaio de IAM,

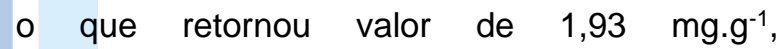
caracterizando o carvão utilizado como deficiente de micro e mesoporos.

O Número de lodo é comumente utilizado para avaliar a quantidade de microporos presentes no carvão e a capacidade do adsorvente de reter moléculas pequenas, já que a molécula de iodo possui tamanho de aproximadamente $0,27 \mathrm{~nm}$ (PIZA, 2008). Foi encontrado para este parâmetro o valor de 255,93 $\mathrm{mg} \cdot \mathrm{g}^{-1}$, inferior aos valores mínimos recomendados pela Associação Americana de Trabalhos com Águas (AWWA) (1974), e pela Associação Brasileira de Normas Técnicas (1991), de 500 e $600 \mathrm{mg}^{-1}{ }^{-1}$, respectivamente, indicando que o CAG utilizado nesse estudo possui baixa quantidade de microporos.

A importância da presença de microporos e mesoporos para a remoção dos $\mathrm{DE}$, foi confirmada por Fukuhara et al. (2006), que constataram a pior remoção de E2 e E1 em carvões com poros de maiores diâmetros. Ademais, Snoeyink e Summers (1999) averiguaram a preferência de adsorção em poros de dimensões semelhantes às da molécula de interesse. Desta forma, era esperada a preferência da adsorção das moléculas de $\mathrm{AM}$ em poros de diâmetro de $1,3 \mathrm{~nm}$, similares aos comprimentos moleculares dos DE analisados no presente estudo, como apresentado na Tabela 1, os quais variam de 1,39 a $1,79 \mathrm{~nm}$, sendo possivelmente adsorvidos em microporos secundários do CA (tamanho de poro no intervalo de 0,8 a 2,0 nm) (FILHO et al., 2017; IUPAC, 1982).

\subsection{Remoção da atividade estrogênica por GAC}

Os ensaios foram realizados na temperatura de $28 \pm 2{ }^{\circ} \mathrm{C}$ e $\circ \mathrm{pH}$ se manteve na ordem de 7 , igualando-se ao $\mathrm{pH}_{\mathrm{pcz}}$. No tocante à qualidade inicial da água de estudo, esta apresentou cor aparente e turbidez abaixo do limite de detecção dos métodos utilizados nas análises, corroborando a qualidade físico-química semelhante à pós-filtração de ETA. A preocupação em uma matriz real, porém com elevada qualidade decorre do intuito de se avaliar o uso da CA após filtração, uma vez que a adsorção é mais eficiente em águas clarificadas, devido à minimização de competição dos sítios ativos, em especial de compostos orgânicos (ALBUQUERQUE et al., 2016; WHO, 2011).

$O$ ensaio YES apresentou valor médio do limite de detecção igual a 0,07 ng.L-1 EQ-E2 $(n=2)$ e $E_{50}$ médio da curva de calibração (concentração que elucida uma atividade igual a $50 \%$ do controle positivo de $17-\beta$-estradiol) de $0,23 \mu \mathrm{g} \cdot \mathrm{L}^{-1}$, valor com uma ordem de grandeza abaixo do comumente encontrado em literatura para tal ensaio, na ordem de $3 \mu \mathrm{g} \cdot \mathrm{L}^{-1}$ (BILA, 2005). Segundo Fischer (2013), os valores de $\mathrm{EC}_{50}$ são variáveis, por exemplo, quanto ao número inicial de células da levedura e quanto ao tempo de incubação desta. Apesar da diferença de valores encontrada para o $\mathrm{EC}_{50}$, a curva padrão utilizada no ensaio apresentou absorbância dentro do esperado, entre 1,5 e 3,5, e a máxima indução também se comportou conforme o reportado por Bila (2005), com média de 2,75, comparados aos $2,98 \pm 0,1$, reportados pela autora.

Assim, com os resultados da quantificação da atividade estrogênica obtidos através do ensaio YES, foi possível a confecção das isotermas, seguindo os modelos de Freundlich e Langmuir (Figuras 4 e 5).

A comparação entre as isotermas e análise de seus parâmetros foi realizada de acordo com Metcalf e Eddy (2016), assim como descrito para o cálculo do IAM. Através da análise dos resultados obtidos é possível concluir que o modelo com melhor ajuste da adsorção dos DE utilizados pelo CAG foi pelo tratamento dos dados segundo o modelo de Langmuir. Desta forma, obteve-se a Equação 6, através da qual é possível estimar a massa necessária do CAG de estudo para obtenção da concentração final dos DE desejada.

$$
\frac{C_{e}}{q_{e}}=0,06+0,002 \times C_{e}
$$

O carvão de estudo foi capaz de remover atividade estrogênica, de maneira diretamente proporcional à adição de maiores massas do mesmo (Figura 6). Debs et al. (2019) também encontraram sinergia entre a dose do adsorvente feito de biomassa de leveduras e eficiência de adsorção de EE2, apesar da natureza do material 
usado ser diferente. Contudo, a remoção dos $\mathrm{DE}$ não foi completa, chegando ao valor máximo de $91,6 \%$ quando adicionada quantidade relativamente alta de CAG, $700 \mathrm{mg} \cdot \mathrm{L}^{-1}$. As concentrações de CA normalmente utilizadas em ETA variam entre 1 e $100 \mathrm{mg} \cdot \mathrm{L}^{-1}$. Nesses casos as medianas das remoções reportadas foram de $89 \%$ a $97 \%$, cabendo ressaltar que tais remoções foram para DE analisados separadamente (AUSTRALIAN GOVERNMENT, 2011; AZEVEDO, 2019; SNYDER et al., 2007; YOON et al., 2003).

Figura 4: Isoterma de Freundlich obtida no tratamento dos dados da adsorção dos DE no CAG em meio aquoso, em escala dilog.

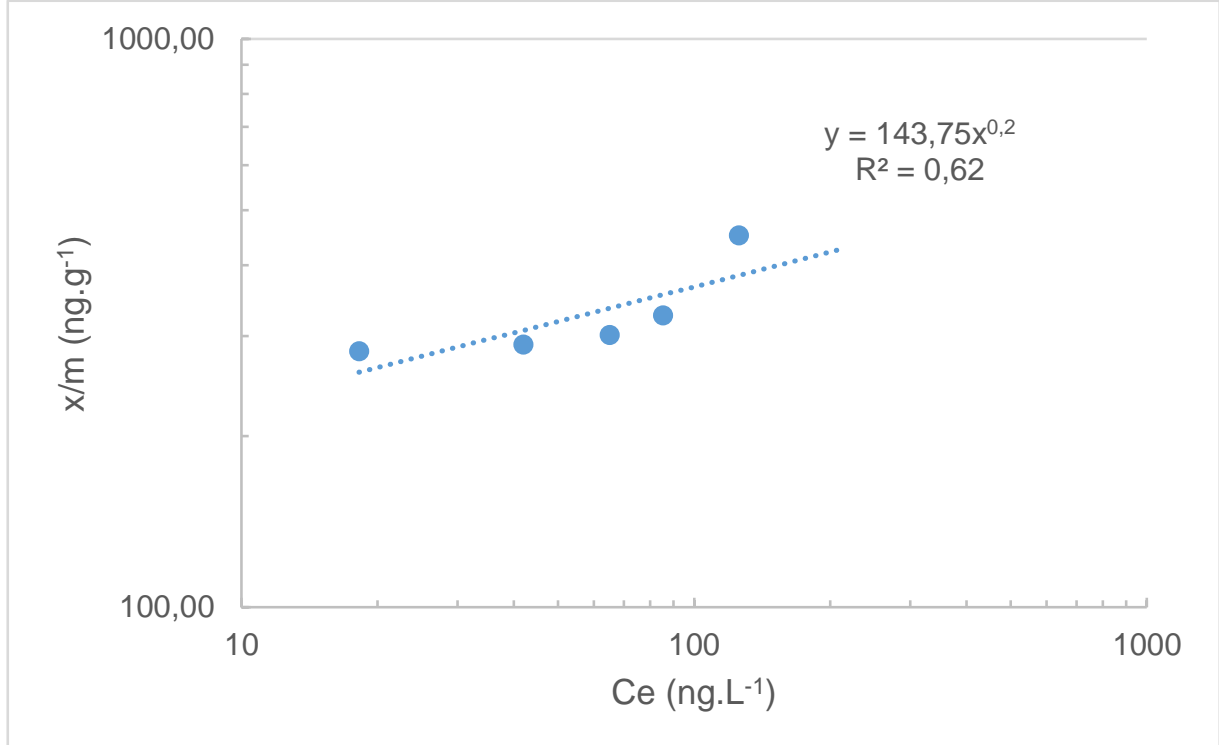

Notas: Temperatura: $28 \pm 2{ }^{\circ} \mathrm{C} ; \mathrm{pH}$ : 7; Tempo de reação: $2 \mathrm{~h}$; Concentração inicial do adsorvato: 215,89 ng. $\mathrm{L}^{-1} \mathrm{EQ}-\mathrm{E} 2$; ${ }^{*} \mathrm{x} / \mathrm{m}$ : massa de adsorvato adsorvido por grama de adsorvente; ${ }^{* \star} \mathrm{Ce}$ : concentração de equilíbrio do adsorvato na solução após a adsorção. Fonte: Autoria Própria

Figura 5: Isoterma de Langmuir obtida no tratamento dos dados da adsorção dos DE no CAG em meio aquoso para a adsorção dos DE no CAG.

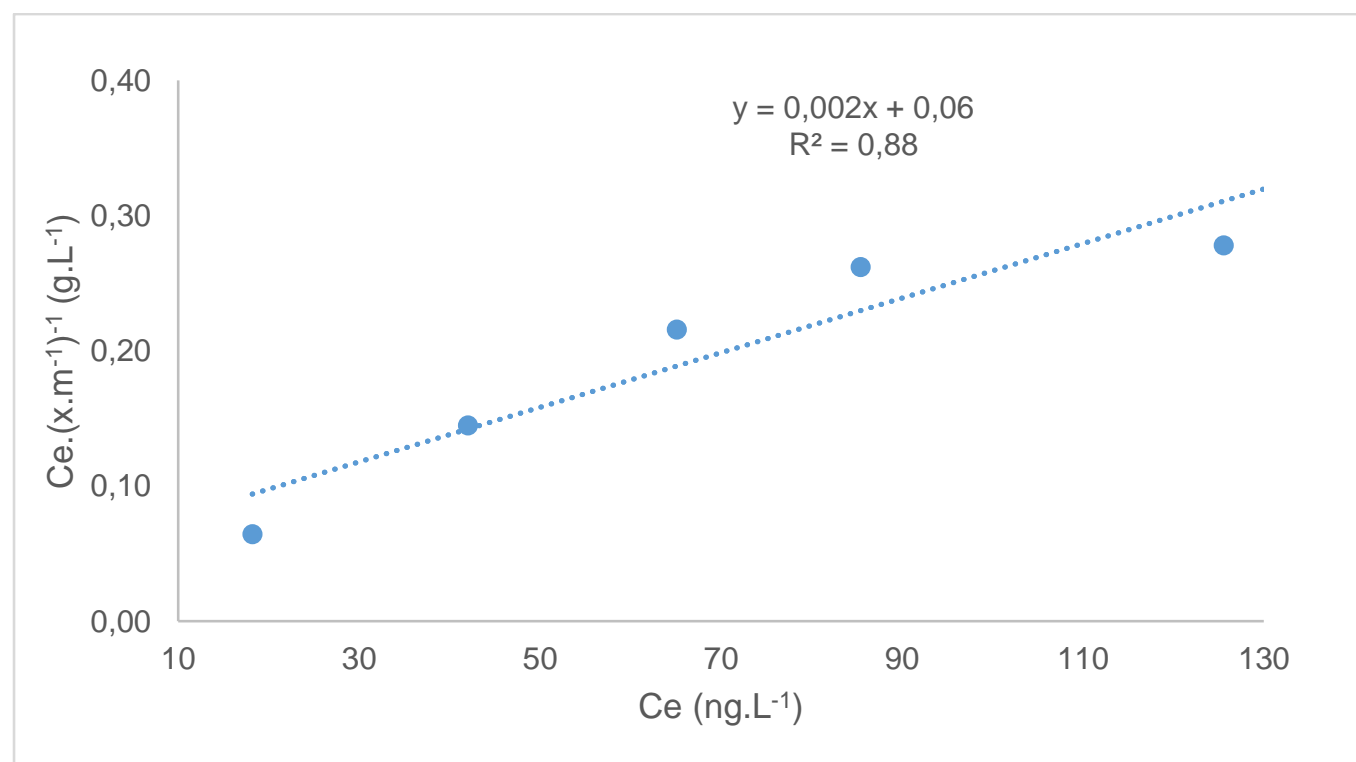

Notas: Temperatura: $28 \pm 2{ }^{\circ} \mathrm{C}$; $\mathrm{pH}$ : 7; Tempo de reação: $2 \mathrm{~h}$; Concentração inicial do adsorvato: 215,89 ng.L${ }^{1}$ EQ-E2; Ce: concentração de equilíbrio do adsorvato na solução após a adsorção; $x / m$ : massa de adsorvato adsorvido por grama de adsorvente, igual a x/m. Fonte: Autoria própria 
Figura 6: Gráfico da remoção da atividade estrogênica da mistura de DE por CAG

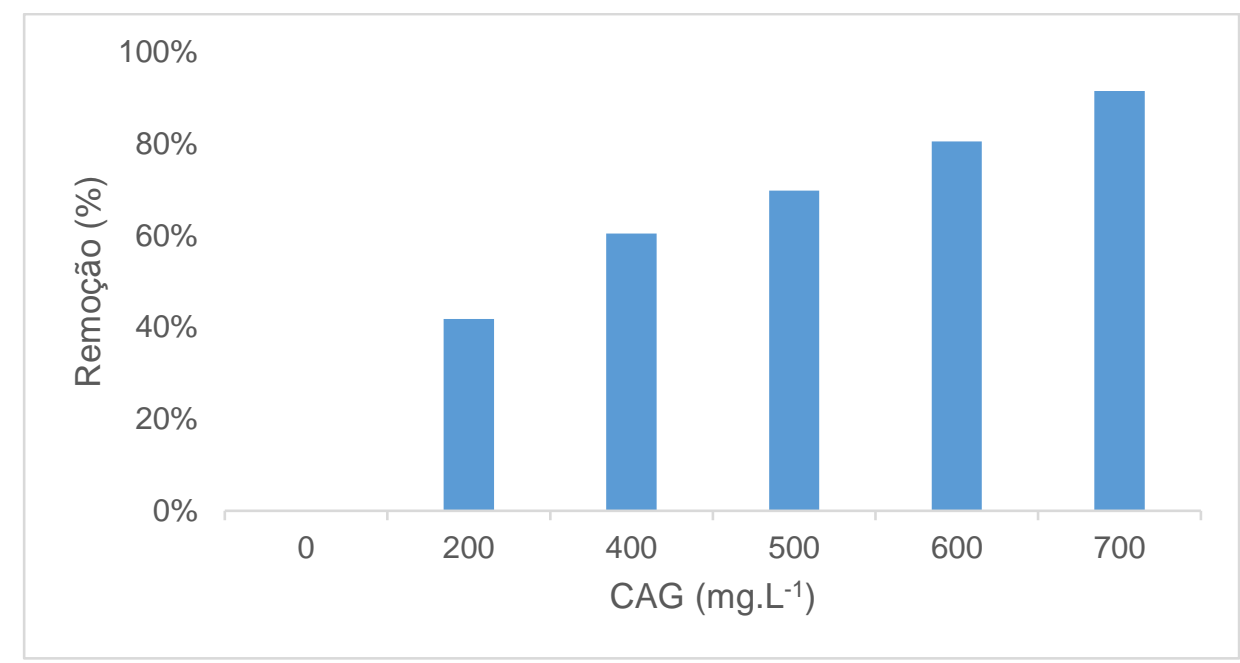

Fonte: Autoria Própria

Tal remoção se mostrou condizente aos resultados de caracterização do carvão, que levaram à inferência da baixa incidência de micro e mesoporos no CAG em questão, que seriam preferenciais à adsorção de moléculas de $\mathrm{DE}$, tal como já mencionado.

Em relação aos outros estudos supracitados que utilizaram concentrações menores de CAG e mostraram remoções similares à do presente trabalho, cabe destacar que os DE foram avaliados de forma separada, o que pode subestimar o real efeito destes compostos, por não considerarem a sinergia que ocorre entre os mesmos, como as que ocorrem no ambiente, que pode aumentar a potência relativa da atividade estrogênica (GOMES et al., 2017). Devido às diferentes características físico-químicas apresentadas na Tabela 1, é possível que o efeito sinérgico varie ao longo do tempo no ambiente $e$ durante o processo de adsorção no CA devido às diferenças de composição da mistura ao longo do tempo. Tudo isso pode ocasionar diferentes potências estrogênicas relativas nos diferentes tempos de contato, além do fato de que os $D E$ podem competir separadamente pelos sítios ativos (METCALF \& EDDY, 2016).

De acordo com Beck et al. (2006) foi possível calcular uma potência estrogênica relativa para a mistura dos DE utilizados nesse estudo que teoricamente deveria se apresentar como 187,52 ng. $\mathrm{L}^{-1} \mathrm{EQ}-\mathrm{E} 2$. Na prática, através do ensaio YES, foi obtido o valor de 215,89 ng.L-1 EQ-E2, 1,15 vezes maior do que o referencial teórico.

Mesmo com o potencial efeito adverso dos $\mathrm{DE}$, a previsão de remoção destas substâncias e seus valores máximos permitidos em matrizes ambientais não estão presentes na legislação de muitos países, incluindo o Brasil. Nesse contexto, destaca-se os Estados Unidos, que inseriram o E1, o E2 e o EE2, por exemplo, na Lista de Contaminantes Candidatos à futura regulamentação em sua quarta atualização (USEPA, 2016). Ainda nesse sentido, Bastos et al. (2009), apresentaram em seu trabalho Valores Máximos Desejáveis (VMD) de E2 em água para consumo humano, a partir da análise da dose diária tolerável sem efeito adverso, resultando em VMD de estradiol de: $5,47 \mathrm{ng} \cdot \mathrm{L}^{-1}$ para lactentes, $8,20 \mathrm{ng} \cdot \mathrm{L}^{-1}$ para crianças e $24,60 \mathrm{ng} \cdot \mathrm{L}^{-1}$ para adultos. Considerando que a máxima remoção obtida nesse estudo foi de $91,6 \%$, equivalente à um residual de 18,19 ng. $L^{-1}$ EQ-E2, ao se compara com o VMD para E2 obtido por Bastos et al. (2009), conclui-se que o processo avaliado atenderia ao VMD máximo reportado por Bastos et al. (2009) para adultos, todavia, o valor ainda é superior ao VMD mínimo de 5,47 ng.L-1, para lactentes.

Em posse desses VMD e por intermédio da Equação 6, a partir da concentração inicial testada de 215,89 ng.L-1 EQ-E2, estimou-se a necessidade de tratar cada litro da água dopada com 2729 mg do CAG para atingir o cenário mais restritivo (para lactentes). De maneira análoga, para o cenário menos restritivo (para adultos) se faz necessária uma dose de 849,19 mg de CAG por litro.

Portanto, foi possível perceber que o Carvão Ativado Granular é capaz de ocasionar a remoção de atividade estrogênica causada pelos 
desreguladores endócrinos estudados. Contudo, se faz necessário o estudo das condições que possam otimizar o processo de adsorção utilizando menores quantidades de CAG e menor tempo de contato a fim de remover completamente os DE. Citam-se as possibilidades de variações de temperatura e $\mathrm{pH}$, utilização do carvão moído, que tende a ter maior área superficial específica. A busca de outro carvão também deve ser considerada, visto que o CA utilizado neste estudo apresentou em sua caracterização baixos índices indicadores de micro e mesoporosidade e, de acordo com as propriedades físico-químicas dos DE utilizados, estes seriam mais bem adsorvidos nesses tipos de poros.

\section{CONCLUSÃO}

Conclui-se que o CAG pode ser utilizado para a remoção de atividade estrogênica, desde que utilizadas quantidades suficientes, uma vez que para atingir $91,57 \%$, foi necessária concentração elevada de CAG (700 mg.L-1), levando em consideração estudos que reportam o uso de massas inferiores, de até $100 \mathrm{mg} \cdot \mathrm{L}^{-1}$.

Para alcançar concentração de EQ-E2 equivalente ao $V M D$ de E2 mais restritiva encontrado no estudo de Bastos et al. (2009), deve-se utilizar uma dose de $2,9 \mathrm{~g}$ do GAC estudado por litro de água contaminada com as concentrações iniciais testadas, de 215,89 ng. L-1.

Destaca-se que este trabalho avaliou uma mistura de DE em baixas concentrações, tal como são encontradas no ambiente, e foi possível constatar o efeito sinérgico da mistura. Tal efeito pode ter influenciado na menor eficiência de remoção observada nesse estudo, uma vez que os resultados foram comparados àqueles obtidos em trabalhos que avaliaram os compostos isoladamente.

Neste contexto recomenda-se a realização de mais estudos que avaliem outras variações capazes de aprimorar a adsorção, além da busca de outro carvão ativado, que tenham maiores quantidades de microporos e mesoporos e maior área específica.

\section{REFERÊNCIAS}

ABNT. ASSOCIAÇÃO BRASILEIRA DE NORMAS TÉCNICAS. MB-3410: Carvão Ativado Pulverizado Determinação do Número de lodo. Rio de Janeiro, 1991.
ADEEL, M.; SONG, X.; WANG, Y.; FRANCIS, D.; YANG, Y. Environmental impact of estrogens on humam animal and plant life: A critical review. Environment International, v. 99, p. 107-119, 2017.

ALBUQUERQUE, M. V.; OLIVEIRA E. G.; BARBOSA, A. S.; RAMOS, R. O.; RODRIGUES, R. M. M.; SÁTIRO, J. R.; LOPES, W. S. Remoção De Cianotoxinas De Água De Abastecimento Público Por Adsorção Em Carvão Ativado. In: Congestas, 2016. Anais do Congresso Brasileiro de Gestão Ambiental e Sustentabilidade - Vol. 4.

APHA; AWWA; WEF. Standard methods for the examination of water and wastewater. Washington, DC: WEF:1368 p. 2005.

AQUINO, S.F.; BRANDT, E.M.F.; CHERNICHARO, C.A.L. Remoção de fármacos e desreguladores endócrinos em estações de tratamento de esgoto: revisão da literatura, Revista de Engenharia Sanitária e Ambiental, v. 18, n.3, p. 187-204, 2013.

ASTM International. Standard Practice for Determination of Adsorptive Capacity of Activated Carbon by Aqueous Phase Isotherm Technique. 2008.

AUSTRALIAN GOVERNMENT. National Water Quality Management Strategy. Australian Drinking Water Guidelines 6. National Health and Medical Research Council, National Resource Management Ministerial Council, Commonwealth of Australia, Canberra, 2011.

AWWA. AMERICAN WATER WORKS ASSOCIATION. B604-74: Standard For Granular Activated Carbon. 1974.

AZEVEDO. T. S. Remoção De Desreguladores Endócrinos Em Água De Abastecimento. Dissertação de Pós-Graduação em Engenharia Civil. Universidade Federal de Viçosa, Viçosa, 2019.

BAÊTA, B. E. L.; RAMOS, R. L. LIMA, D. R S E AQUINO, S. F. Use of submerged anaerobic membrane bioreactor (SAMBR) containing powdered activated carbon (PAC) for the treatment of textile effluents. Water Science and Technology, v. 65, n. 9, p. 1540 1547, 2012.

BASTOS, R.K.X.; BEVILACQUA, P.D.; MIERZWA, J.C. Análise de Risco Aplicada ao Abastecimento de Água para Consumo Humano. In: PÁDUA, V.L.P. (Coord.) Remoção de microrganismos emergentes e microcontaminantes orgânicos no tratamento de água para consumo humano. Belo Horizonte: Ed. ABES, p. 327-360, 2009.

BECK, I. C., BRUHN, R., GANDRASS, J. Analysis of Estrogenic Activity in Coastal Surface Waters of the 
Baltic Sea Using the Yeast Estrogen Screen. Chemosphere, v. 63, pp. 1870-1878, 2006.

BERNI, J.V.; MEDEIROS, J. F.; CESARO, J.P.V.; DAMASCENO, B. B.; DIORIO, A.; SCHEUFELE, F. B.; VIEIRA, M. F. Avaliação Do Tratamento Químico Do Epicarpo De Açaí Visando A Remoção De Antibióticos Em Solução Aquosa. In: $6^{\circ}$ Simpósio de Biotecnologia na Agroindústria. Revista Brasileira de Energias Renováveis. Palotina, PR. 2017.

BILA, D. M. Degradação e remoção da atividade estrogênica do desregulador endócrino 17ßestradiol pelo processo de ozonização. Tese de doutorado em Ciências em Engenharia Química. Universidade Federal do Rio de Janeiro, COPPE, Rio de Janeiro, 2005.

BILA, D.M.; DEZOTTI, M. Desreguladores endócrinos no meio ambiente: efeitos e conseqüências. Química Nova, v. 30, n.3, p. 651-666, 2007.

BORNMAN, M. S.; ANECK-HAHN, N.H.; JAGER, C.; HEINDEL, J.J. Endocrine disruptors and health effects in Africa: a call for action. Environmental Health Perspectives, v. 125, n. 8, 2017.

BOTTREL, S.E.C. Avaliação Da Remoção Da Etilenotiouréia (Etu) E 1,2,4-triazol Através De Processos Oxidativos Avançados E Adsorção. Dissertação de mestrado, em Saneamento, Meio Ambiente e Recursos Hídricos. Universidade Federal de Minas Gerais, Belo Horizonte, 2012.

CARVALHO, A.R.; CARDOSO, V.; RODRIGUES, A.; BENOLIEL, M.J.; DUARTE, E. Fate and Analysis of Endocrine-Disrupting Compounds in a Wastewater Treatment Plant in Portugal. Water Air Soil Pollut, 227:202, 2016.

CHEN, C.Y.; WEN, T.Y.; WANG, G.S.; CHENG, H.W.; LIN, Y.H.; LIEN, G.W. Determining estrogenic steroids in Taipei waters and removal in drinking water treatment using High-flow solid-phase extraction and liquid chromatography/tandem mass spectrometry. Science of the Total Environment, v. 378 , n.3, p. 352-365, 2007.

CUNHA, I.N.; AGUILA, K.S. Avaliação da presença de hormônios em manancial de abastecimento João Leite em Goiânia-GO. In: ABES. 28음 Congresso Brasileiro de Engenharia Sanitária e Ambiental. Rio de Janeiro, 2015.

DEBS, K. B. ; Silva, H.D.T ; MORAES, M. L. L. ; CARRILHO, E. N. V. M. ; LEMOS, S. G. ; Labuto, Geórgia . Biosorption of 17alfa-ethinylestradiol by yeast biomass from ethanol industry in the presence of estrone. Environmental Science and Pollution Research , v. 26, p. 28419-28428, 2019.
DI BERNARDO, L; DANTAS, A. D. Métodos e Técnicas de Tratamento de Água, 2ed. Editora Rima, 2005.

DIAS, R.V.A.; SANSON, A.L.; AFONSO, R.J.C.F.; AQUINO, S.F.; PADUA, V.L. Avaliação da ocorrência de fármacos e interferentes endócrinos em sistema de abastecimento de água na região metropolitana de Belo Horizonte. In: ABES. 28으 Congresso Brasileiro de Engenharia Sanitária e Ambiental. Rio de Janeiro, 2015

DING, W.H.; TZING, S.H. Analysis of nonylphenol polyethoxilates and their degradation products in river water and sewage effluent by gas chromatography-ion trap (tandem) mass spectrometry and electron impact and chemical ionization. Journal of Chromatography, v. 824, p 79-90, 2001.

ESTRADA-ARRIAGA, E.; MIJAYLOVA, N. A comparison of biodegradation kinetic models applied to estrogen removal with nitrifying activated sludge. Water Science \& Technology, v. 62, n. 9, 2010.

FILHO, F. M. T.; PASCHOALATO, C.F.P.R.; JUNIOR, R. P. Remoção De Clorofórmio Por Adsorção Em Carvão Ativado Granular. In: ABES. Congresso ABES FENASAN. 2017.

FISCHER, N. Cloração da água com 17ß-estradiol e utilização do teste YES para avaliação da estrogenicidade. Dissertação de mestrado em Ciências em Engenharia Hidráulica e Saneamento. Universidade de São Paulo, Escola de Engenharia de São Carlos, São Carlos, 2013.

FORMICA, B. C.; BRUDZINSKI, P. B.; CARVALHO, K. Q.; FLORIANO, J. B. ; PASSIG, F. H.; LIZ, M. V. Caracterização e Avaliação das Propriedades Adsortivas da Casca de Laranja na Remoção do Corante Direct Blue 86. Virtual Quimica. v.9, p. 608625, 2017.

FOUST S.A; WENZEL A.; CLUMP W.C.; MAUS L.; ANDERSEM B.L. Princípios das Operações Unitárias. Rio de Janeiro: LTC - Livros Técnicos e Científicos, 2ª Edição, 1982.

FUERHACKER, M.; DÛRAUER, A.; JUNGBAUER, A. Adsorption isotherms of $17 ß$-estradiol on granular activated carbon (GAC). Chemosphere, v.44, n.7, p.1573-1579, 2001.

FUKUHARA, T.; IWASAKI, S.; KAWASHIMA, M.; SHINOHARA, O.; ABE, I. Adsorbability of estrone and $17 \mathrm{~b}$-estradiol in water onto activated carbon. Water Research. v.40, p. 241-248, 2006.

GOMES, G.; FELIX, L.; ARGOLO, A.S.; BILA, D.M. Avaliação Da Atividade Estrogênica De Substâncias 
Simples E Misturas Pelo Ensaio Yes (Yeast Estrogen Screen). In: ABES. Congresso ABES FENASAN. 2017.

GUILARDUCI, V.V.S.; MESQUITA, J.P.; MARTELLI, P.B.; GORGULHO, H.F. Adsorção De Fenol Sobre Carvão Ativado Em Meio Alcalino. Química Nova. v.29, n.6, p. 1226-1232. 2006.

IFA - INSTITUTE FOR OCCUPATIONAL SAFETY AND HEALTH OF GERMAN SOCIAL ACCIDENT INSURANCE. GESTIS Substance Database. Disponível em: <http://gestisen.itrust.de/nxt/gateway.dll/gestis_en/570052.xml?f=te mplates $\$$ fn=default.htm $\$ 3.0>$. Acesso em: 20 ago 2019, 20:05.

INMET - INSTITUTO NACIONAL DE METEOROLOGIA E ESTATíSTICA. Consulta Dados da Estação Convencional: JUIZ DE FORA (MG). Disponível em: <http://www.inmet.gov.br/sim/sonabra/dspDadosCodig o.php?ODM2OTI=>. Acesso em: 01 nov de 2019, 17:45.

IUPAC. União Internacional de Química Pura e Aplicada. Reporting Physisoption data for gás/solid systems, v. 54, p. 2201-2218, 1982.

JOHNSON, A.C.; BELFROID, A.; DI CORCIA, A. Estimating steroid inputs into activated sludge treatment works and observations on their removal from the effluent. The Science of the Total Environmental, v.256, p. 163-173, 2000.

KOLPIN, D.W.; FURLONG, E.T.; MEYER, M.T.; THURMAN, E.M.; ZAUGG, S.D.; BARBER, L.B.; BUXTON, H.T. Pharmaceuticals, Hormones, and Other Organic Wastewater Contaminants in U.S. Streams, 1999-2000: A National Reconnaissance. Environmental Science \& Technology, v.36, n. 6, p. 1202-1211, 2002.

LIBANIO, M. Fundamentos de Qualidade e Tratamento, 3d. Campinas: Ed. Átomo. 2010.

LIMA, D. R. S.; LIBANIO, M.; AFONSO, R. C. F.; AQUINO, S. F. Avaliação da remoção de fármacos e desreguladores endócrinos de águas de abastecimento por clarificação em escala de bancada. Química Nova, v. 37, p. 783-788, 2014.

LIU, Z-H.; KANJO, Y.; MIZUTANI, S. Removal mechanisms for endocrine disrupting compounds (EDCs) in wastewater treatment - physical means, biodegradation, and chemical advanced oxidation: A review. Science of the Total Environment, v. 407, p. 731-748, 2009.
METCALF, L.; EDDY, H. P. Tratamento de efluentes e recuperação de recursos. 5. ed. Porto Alegre: AMGH, 2016.

MOREIRA, D.S.; AQUINO, S. F.; AFONSO, R. J. C. F.; SANTOS, E. P. P. C.; PÁDUA, V.L. Occurrence of endocrine disrupting compounds in water sources of Belo Horizonte Metropolitan Area, Brazil. Environmental Technology, v.30, n.10, p.1041-1049, 2009.

MOREIRA, M.A.; AQUINO, S.F.; COUTRIM, M.X.; SILVA, J.C.C.; AFONSO, R.J.C.F. Determination of endocrine-disrupting compounds in waters from Rio das Velhas, Brazil, by liquid chromatography/high resolution mass spectrometry (ESILC-IT-TOF/MS). Environmental Technology, v.32, n.11-12, p.14091417, 2011.

NASCIMENTO, R. F.; LIMA, A. C. A.; VIDAL, C. B.; MELO, D. Q.; RAULINO, G. S. C. Adsorção: Aspectos Teóricos e Aplicações Ambientais. Imprensa Universitária, Fortaleza, 2014.

OGATA, F.; TOMINAGA, H.; YABUTANI, H.; KAWASAKI, N. Removal of estrogens from water using activated carbon and ozone. Journal of Oleo Science, v.60, n.12, p.609-611, 2011.

PEREIRA, R.O. Formação de subprodutos do estrona e $17 \beta$-estradiol na oxidação utilizando cloro e o ozônio em água. Tese de Doutorado em Engenharia Hidráulica e Saneamento. Universidade de São Paulo, USP. São Carlos, 2011.

PEREIRA, R.O.; POSTIGO, C.; de ALDA, M.L.; DANIEL, L.A.; BARCELÓ, D. Removal of estrogens through water disinfection processes and formation of by-products. Chemosphere, v. 82 , n. 6, p. 789-799, 2011.

PIZA, A.V.T. Avaliação da Capacidade Adsortiva de Carvões Ativados para a Remoção de Diuron e Hexazinona. Dissertação de Pós-Graduação em Tecnologia Ambiental do Centro de Ciências Exatas Naturais e Tecnológicas da Universidade de Ribeirão Preto, Ribeirão Preto, 2008.

RESENDE, T. C.; NETO, J. M.; AZEVEDO, T. S.; BOTTREL, S. E. C.; PEREIRA, R. O. Estudo Comparativo Entre as Concentrações de Hormônios Reportados em Matrizes Ambientais Aquosas no Brasil e no Exterior.In: ABES. Congresso ABES FENASAN. São Paulo. 2017.

ROUTLEDGE, E. J.; SUMPTER, J. P. Estrogenic activity of surfactants and some of their degradation products assessed using a recombinant yeast screen. Environmental Toxicology and Chemistry, v. 15, $\mathrm{n}$. 3, p. 241-248, 1996. 
SENE, L. Comparação do desempenho de carvão ativado produzido a partir de diferentes matrizes para remoção de microcistina-LR de águas de abastecimento. Dissertação de mestrado em Engenharia Hidráulica e Saneamento. Universidade de São Paulo, USP. São Carlos, 2017.

SNOEYINK, V. L.; SUMMERS, R.S. Adsorption of organic compounds. Cap. 13. Water Quality and Treatment: A Handbook of Community Water Spplies. (Ed. Letterman, R. D.). 5a ed. McGraw Hill Education. 1999.

SNYDER, S.A.; ADHAM, S.; REDDING, A.M.; CANNON, F.S.; DECAROLIS, J.; OPPENHEIMER, J.; WERT, E.C.; YOON, Y. Role of membranes and activated carbon in the removal of endocrine disruptors and pharmaceuticals. Desalination, v. 202, n. 1, p. 156181, 2007.

SOLÉ, M.; ALDA, M.J.L; CASTILLO, M.; PORTE, C.; LADEGAARD-PEDERSEN, K.; BARCELÓ, D. Estrogenicity Determination in Sewage Treatment Plants and Surface Waters from the Catalonian Area (NE Spain), Science of the Total Environment, v.34, n. 24, p. 5076-5083, 2000.

USEPA - UNITED STATES ENVIRONMENTAL PROTECTION AGENCY. Contaminant Candidate List-4-CCL4. 2016. Disponível em: https://www.epa.gov/ccl/contaminant-candidate-list-4ccl-4-0. Acesso em: 01 nov 2019, 17:04.

USEPA - UNITED STATES ENVIRONMENTAL PROTECTION AGENCY. Endocrine Disruption.
Disponível em: https://www.epa.gov/endocrinedisruption. Acesso em: 20 ago 2019, 20:30.

VILELA, C.L.E.; BASSIN, J.P.; PEIXOTO, R.S. Water contamination by endocrine disruptors: Impacts, microbiological aspects and trends for environmental protection. Environmental Pollution, v.235, p.546559, 2018.

WESTERHOFF, P.; YOO N, Y.; SNYDER, S.; WERT, E. Fate of endocrine-disruptor, pharmaceutical, and personal care product chemicals during simulated drinking water treatment processes. Environmental Science \& Technology, v. 39, p. 6649-6663, 2005.

WHO. WORLD HEALTH ORGANIZATION. Guidelines for drinking-water quality. 4th ed. 2011.

YANGALI-QUINTANILLA, V., SADMANI, A., MCCONVILLE, M., KENNEDY, M., AMY, G. Rejection of pharmaceutically active compounds and endocrine disrupting compounds by clean and fouled nanofiltration membranes. Water Research, v. 43, p. 2349-2392, 2009.

YOON, Y.; WESTERHOFF, P.; SNYDER, S.A.; ESPARZA, M. HPLC-fluorescence detection and adsorption of bisphenol A, 17 $\beta$-estradiol, and $17 \alpha-$ ethynyl estradiol on powdered activated carbon. Water Research, v. 37, n. 14, p. 3530-3537, 2003.

ZAGO. J.F. Influência das Características FísicoQuímicas de Carvões Ativados na Adsorção de Saxitoxinas. Tese de Doutorado em Tecnologia Ambiental e Recursos Hídricos. Universidade de Brasília. Brasília-DF. 2010. 